\title{
COMPLETE TRANSPOSITION OF THE GREAT VESSELS
}

\author{
BY \\ ROY ASTLEY AND CLIFFORD PARSONS
}

From The Children's Hospital, Birmingham

Received June 21, 1951

In complete transposition of the great vessels the relative positions of aorta and pulmonary artery are reversed. Venous blood drains, as normally, into the right side of the heart but is returned immediately to the aorta: oxygenated blood passes from the pulmonary veins into the left side of the heart but is pumped through the pulmonary artery back to the lungs. The two circulations are independent and survival is possible only if other cardiac defects allow shunts of blood from each circuit to the other.

Such different views have been expressed recently about the diagnostic value of the X-ray silhouette, and about the prognosis that the time is ripe to attempt to explain and reconcile some of these differences. This paper is based on a study of 16 children with complete transposition: eleven were boys and five girls. The diagnosis has either been confirmed by necropsy or, in the surviving patients, is based on clinical and radiological evidence.

Incidence. Keith (1948) gives the incidence of complete transposition as about 10 per cent of all cases of congenital heart disease.

Of 300 children with congenital heart disease seen at the Birmingham Children's Hospital in eighteen months, 72 were cyanosed; 36 suffered from Fallot's tetralogy and 16 from complete transposition. This suggests the importance of the condition to the pædiatrician. During this same eighteen months, 24 cyanosed children died; 9 had complete transposition and 6 Fallot's tetralogy. Since there is such a difference in the prognosis of the two conditions and as only one is readily amenable to surgery, it is highly desirable that an accurate diagnosis should be made early in infancy.

\section{Diagnosis: Clinical Picture}

The symptoms and signs that we have found helpful in distinguishing transposition from Fallot's tetralogy are enumerated in Table I. Almost always cyanosis was noticed at the time of delivery;

TABLE I

Symptoms and Signs in 16 Cases of Complete Transposition

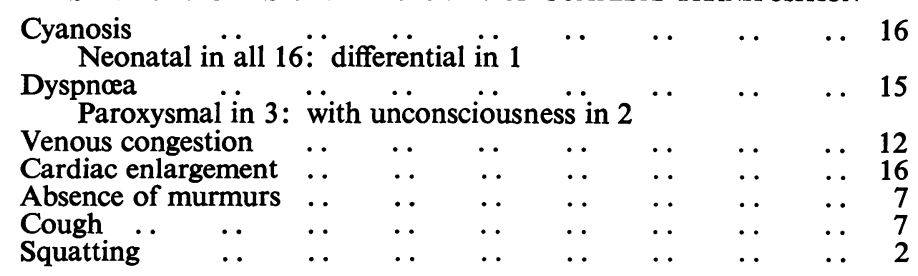

there was often difficulty in establishing respiration and five babies were thought in the first instance to be suffering from cerebral birth injury or pulmonary atelectasis. The onset of cyanosis might be delayed for a few hours. Its depth was increased by crying, coughing, or exposure to cold, and sometimes by feeding, and it is especially noteworthy that the child's colour improved very slowly, 
or not at all, when oxygen was administered. Three patients who were severely cyanosed at birth later had such a good colour that they were thought to have uncomplicated septal defects. Emerson and Green (1942) mentioned that cyanosis might not be severe, and one of our children at the age of two years had a colour that was almost normal.

Tausigg (1947) pointed out that differential cyanosis, in which the lower part of the body is less deeply cyanosed than the upper part, is a sure sign of transposition. We have observed this phenomenon once. The infant died when only a few days old and, although the diagnosis is said to have been confirmed at necropsy, we have omitted the case from the series as it has been impossible to obtain adequate particulars.

Associated with the cyanosis there was moderate polycythæmia, averaging about 6.5 million red cells and 120 per cent hæmoglobin, and with a packed cell volume of 65 per cent. Clubbing was usually first seen at about the age of six months.

Panting was often a striking feature and has been noticed even in the youngest infants. Only twice was respiratory distress insufficient to excite comment, yet only three children have suffered from paroxysmal dyspnœa. About half the infants were difficult to feed and weight gain was nearly always slow. Development was delayed and activity severely limited, although one child was able to cover more than a mile if she walked slowly. The squatting or knee-elbow position was seldom effective in relieving respiratory distress.

Coughing was commoner than in Fallot's tetralogy. One child had anginal pain. Congestive cardiac failure was extremely common: distended neck veins and enlargement of the liver sometimes persisted for long periods with little change and digitalis was often needed; venesection helped one baby. Campbell and Suzman (1951) have commented on the frequency of distended veins in the fingers in cases of partial and complete transposition and we also have noticed this. Enlargement of the heart was difficult to recognize clinically during the first week of life, but quickly became obvious and a præcordial bulge sometimes developed. As in Fallot's tetralogy the second sound at the base varied greatly in quality and intensity. A thrill was unusual and nearly half the cases had no murmur. When present, murmurs were usually soft, systolic, and best heard in the third left space close to the sternum; but the majority of Mannheimer's (1949) cases had loud murmurs. In two children a diastolic murmur could be heard. "The sooner murmurs and thrills are disregarded the easier the diagnostic problem" (Taussig, 1947).

In summary, therefore, only one symptom can be regarded as diagnostic and that is the rare one of differential cyanosis of upper and lower extremities. However, as a means of distinguishing transposition from Fallot's tetralogy it is worth remembering that the colour and distress of infants with transposition are rarely improved either by placing them in the knee-elbow position or by administering oxygen. Coughing is often sufficient to excite comment, the heart is large, murmurs are frequently lacking, and chronic venous congestion is common.

\section{RADIOLOGY}

Contradictory views have been expressed about the radiographic appearance of complete transposition. Eek (1949) believes that, " As a rule the diagnosis is simple since the characteristic roentgen picture appears as early as the first months of life." On the other hand Castellanos $e t$ al. (1950) say: "The object of this investigation is to demonstrate that the cardiac outline has no value whatever in the diagnosis of transposition of the great vessels." Similarly Kerley (1951) says: "As the great vessels in infants cannot normally be identified there is little prospect of diagnosing these anomalies without angiocardiography."

According to Taussig (1947), the outstanding diagnostic feature is the narrow shadow cast by the great vessels in the frontal projection, with increase in width as the child is rotated into the left anterior oblique position. Frequently there is also a concave left middle cardiac segment, pulmonary congestion, and enlargement of both ventricles. Eek accepts the narrow vascular pedicle as the typical finding and describes a considerably enlarged heart as of a "characteristic egg-shape, with 
the most pointed end corresponding to the apex in all cases." Campbell and Suzman (1951) commonly found a concavity in the púlmonary conus region, together with mottled lung fields, and dilated, pulsatile, pulmonary arteries. Wood (1950a) says simply that the diagnosis is usually easy and depends on " the recognition of pulmonary plethora in an obviously cyanotic child."

We cannot easily accept either of these extreme views. Although we do not believe that in infancy the diagnosis of complete transposition from direct X-rays and fluoroscopy is necessarily easy, we consider it is generally possible. Fig. 1 shows the cardiac silhouettes of 10 proved and 4 probable cases of complete transposition that were examined radiologically; further details are given in Table II. At first sight Castellanos's views seem to be justified. The shape of the heart in the different patients varies widely, sometimes even in the same individual at different ages. Cardiac enlargement may be of any degree and the heart may lie either transversely or obliquely. The heart shadow may extend some way or only slightly to the right of the spine, the left middle segment may
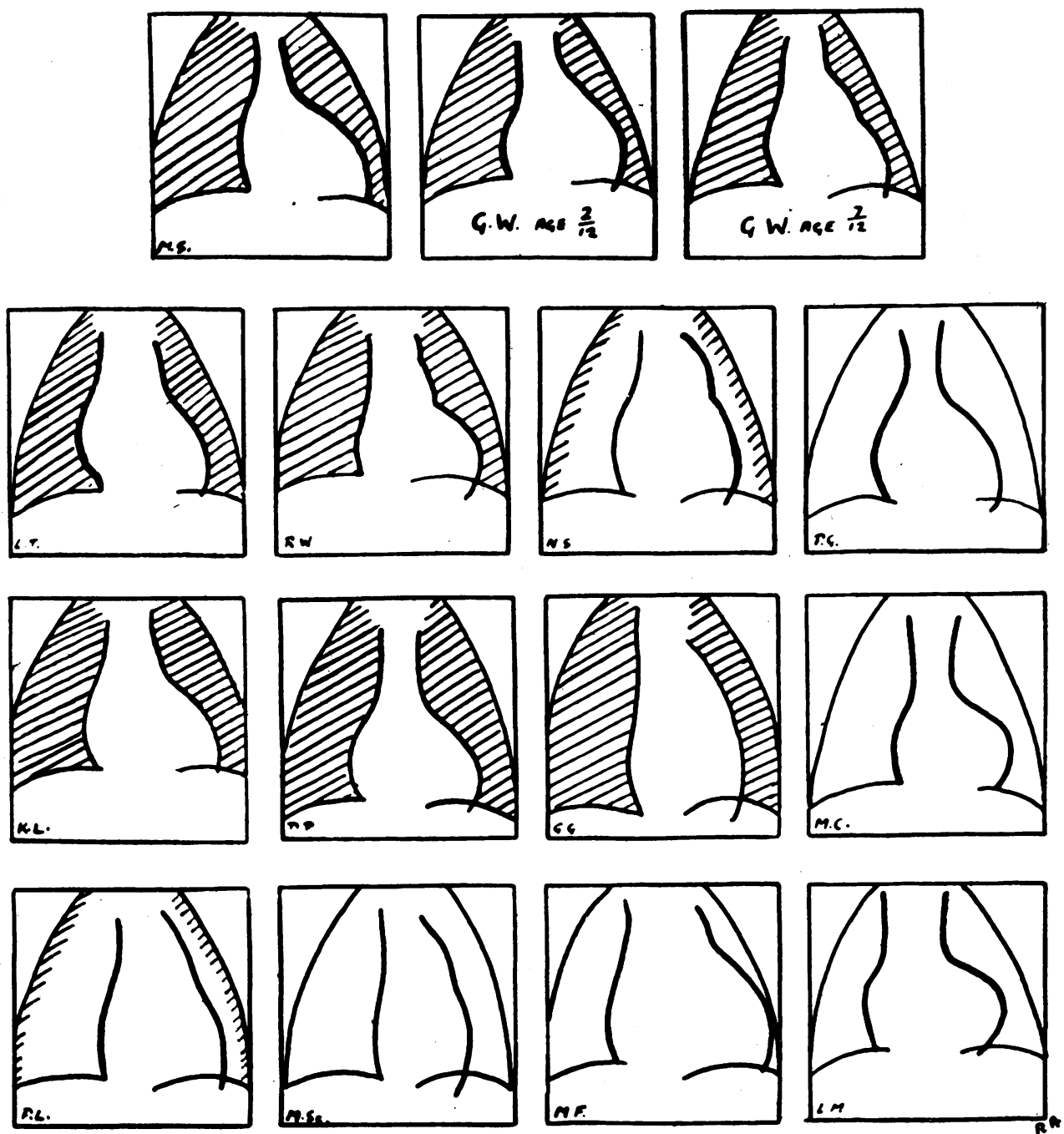

FIG. 1.-The cardiac silhouettes of 14 children with complete transposition of the great vessels. One child (G. W., top right) is shown twice, to demonstrate the variation of heart shape with age. (Shading indicates the presence of pulmonary congestion; partial shading means slight congestion and unshaded lungs are normal or oligæmic.) 
TABLE II

Radiological Findings in 14 Children With Complete Transposition

\begin{tabular}{|c|c|c|c|c|c|c|c|c|c|c|c|}
\hline \multirow{2}{*}{ Name } & \multirow{2}{*}{$\begin{array}{l}\text { Age when } \\
\text { examined }\end{array}$} & \multicolumn{2}{|c|}{ Lungs } & \multirow{2}{*}{$\begin{array}{c}\text { Cardio- } \\
\text { thoracic } \\
\text { ratio }\end{array}$} & \multirow{2}{*}{$\begin{array}{l}\text { Extent of } \\
\text { heart to } \\
\mathbf{R} . \text { of spine }\end{array}$} & \multirow{2}{*}{ Apex } & \multirow{2}{*}{$\begin{array}{l}\text { Vascular } \\
\text { pedicle }\end{array}$} & \multirow{2}{*}{$\begin{array}{c}\text { Left } \\
\text { middle } \\
\text { segment }\end{array}$} & \multirow{2}{*}{$\begin{array}{c}\text { Left } \\
\text { anterior } \\
\text { oblique } \\
\text { view }\end{array}$} & \multirow{2}{*}{$\underset{\text { swallow* }}{\text { Barium }}$} & \multirow{2}{*}{$\begin{array}{c}\text { Confirmatory } \\
\text { evidence* }\end{array}$} \\
\hline & & $\begin{array}{l}\text { Vascu- } \\
\text { larity }\end{array}$ & $\begin{array}{c}\text { Hilar } \\
\text { pulsation }\end{array}$ & & & & & & & & \\
\hline M.C. & 4 days & Normal to & & 61 & Little & $\begin{array}{l}\text { Elevated } \\
\text { like Fallot }\end{array}$ & Narrow & Concave & & & P.M.*1 \\
\hline L.M. & 2 weeks & Poor & & 58 & Con- & Elevated & Normal & Concave & & & P.M.*2 \\
\hline P.G. & 4 weeks & $\begin{array}{c}\text { Normal to } \\
\text { poor }\end{array}$ & ? absent & 60 & $\begin{array}{l}\text { Con- } \\
\text { siderable }\end{array}$ & & Narrow & Concave & $\mathbf{L V +}$ & $\mathbf{N}$ & P.M.*3 \\
\hline M.F. & 3 months & Poor' & & 73 & $\begin{array}{l}\text { Con- } \\
\text { siderable }\end{array}$ & & Wide & $\begin{array}{l}\text { Slightly } \\
\text { prominent }\end{array}$ & $\mathbf{L V +}$ & $\mathbf{N}$ & \\
\hline M.S. & 9 months & ++ & ++ & 65 & Normal & Elevated & $\begin{array}{l}\text { Very } \\
\text { narrow }\end{array}$ & Concave & $\mathbf{L V}>\mathbf{R V}$ & $\mathrm{LA}+* 4$ & $\begin{array}{l}\text { A., C. and } \\
\text { P.M. } * 5\end{array}$ \\
\hline G.W. & 10 months & ++ & + & 67 & $\begin{array}{l}\text { Con- } \\
\text { siderable }\end{array}$ & & & $\begin{array}{l}\text { Prominent (flat } \\
\text { at six weeks) }\end{array}$ & $\begin{array}{l}\mathbf{L V +}, \\
\mathbf{R V +}\end{array}$ & N. & ${ }^{A} 6$ and P.M. \\
\hline P.L. & 1 year & + & & 51 & Little & & $\begin{array}{l}\text { Rather } \\
\text { wide }\end{array}$ & $\begin{array}{l}\text { Long, flat } \\
\text { bulge }\end{array}$ & $\mathbf{L}+$ & N. & A. $* 7$ \\
\hline D.P. & $1 \frac{1}{2}$ years & ++ & & 63 & $\begin{array}{l}\text { Con- } \\
\text { siderable }\end{array}$ & & Narrow & Concave & & & \\
\hline N.S. & 2 years & + & & 59 & $\begin{array}{l}\text { Con- } \\
\text { siderable }\end{array}$ & & Normal & $\begin{array}{l}\text { Long, flat } \\
\text { bulge }\end{array}$ & $\mathbf{L V}>\mathbf{R V}$ & N. & A. $* 8$ \\
\hline $\begin{array}{l}\text { R.W. } \\
\text { L.T. }\end{array}$ & $\begin{array}{l}3 \text { years } \\
3 \text { years }\end{array}$ & $\begin{array}{l}+t \\
++\end{array}$ & $\begin{array}{c}++ \\
+\end{array}$ & $\begin{array}{l}58 \\
66\end{array}$ & $\begin{array}{l}\text { Little } \\
\text { Con- } \\
\text { siderable }\end{array}$ & & $\begin{array}{l}\text { Normal } \\
\text { Wide }\end{array}$ & $\begin{array}{l}\text { Slight bulge } \\
\text { Concave }\end{array}$ & $\begin{array}{l}\mathbf{L V}>\mathbf{R V} \\
\mathbf{R V}>\mathbf{L V}\end{array}$ & $\begin{array}{l}\text { N. } \\
\text { N. }\end{array}$ & $\begin{array}{l}\text { A.*9 } \\
\text { A., C. and } \\
\text { P.M. } * 10\end{array}$ \\
\hline $\begin{array}{l}\text { G.G. } \\
\text { M.Sc. }\end{array}$ & $\begin{array}{l}4 \text { years } \\
4 \text { years }\end{array}$ & $\underset{\text { Poor }}{+t}$ & $\underset{\text { Absent }}{\stackrel{+}{+}}$ & $\begin{array}{l}57 \\
47\end{array}$ & $\begin{array}{l}\text { Little } \\
\text { Little }\end{array}$ & & $\begin{array}{l}\text { Wide } \\
\text { Normal }\end{array}$ & $\begin{array}{l}\text { Long bulge } \\
\text { Very long and }\end{array}$ & $\begin{array}{l}\mathbf{R V +} \\
\mathbf{R V +}\end{array}$ & $\begin{array}{l}{ }^{1} 11 \\
\mathrm{LA}+* 12\end{array}$ & C. and $O$. \\
\hline K.L. & 5 years & $+t$ & + & 53 & Normal & & Normal & Concave & $\mathbf{L V}>\mathbf{R V}$ & N. & \\
\hline
\end{tabular}

* N=Normal, P.M. = Post-mortem examination, $\mathrm{C}=$ Cardiac catheterization, $\mathrm{A}=$ Angiocardiography, and $\mathrm{O}=$ Operation.

*1. Necropsy: Complete transposition. Pulmonary artery normal width. Right ventricle larger than left ventricle. No septal defects. Wide patent ductus.

*2. Necropsy: Complete transposition. Hypoplastic pulmonary artery. Large V.S.D.

*3. Necropsy: Complete transposition. Pulmonary artery normal width. No septal defects. Patent foramen ovale. Ductus closed.

*4. Extra impression on the anterior aspect of the barium-filled esophagus, at the level of T.5, which slopes upwards from left to right.

*5. Angiocardiogram: Type 2. Aorta arises well to left, over outflow of right ventricle, ascends towards right and arches over left bronchus. High concentration in aorta: heart is empty in $2 \frac{1}{2}$ sec. No main pulmonary artery seen and little diodone in lungs. Catheterization: Equal saturations in right chambers. Necropsy: Complete transposition. Small high V.S.D.

*6. Angiocardiogram: Type 1. AP. Aorta from right ventricle near midline. High concentration in aorta but none in main pulmonary artery. Heart empty in 43 sec. LAO. Right heart empties into aorta in 2 sec. Some diodone in left ventricle and right pulmonary artery in later films but no main pulmonary artery from right. Necropsy: Complete transposition. Aorta and pulmonary artery side by side. High V.S.D.

*7. Angiocardiogram: Type 2. Aorta arises well to left and constitutes left mid segment as it ascends to arch over left bronchus. No main pulmonary artery filling seen.

*8. Angiocardiogram: Type 2. Aorta arises well to left and constitutes left mid segment as it ascends to arch over left bronchus. High concentration in aorta: heart nearly empty at $2 \mathrm{sec}$; a little in lungs but no main pulmonary artery filling seen.

*9. Angiocardiogram: Type 2. Very similar to 8. Right chambers large.

*10. Angiocardiogram: Type 1. Aorta arises near midline, like Fallot. High concentration in aorta but main pulmonary artery filling not seen. Little in lungs. Heart empty in 3 sec. Catheterization: No left to right shunt but catheter thought to pass through V.S.D. Necropsy: Complete transposition. Septal defect between right ventricle and left atrium.

*11. Deep aortic impression on left lateral aspect of œsophagus.

*12. Extra impression of the left and anterior aspects of the barium-filled œsophagus, above the level of the aortic arch.

*13. Catheterization: Right ventricular pressure high. Shunt from left to right ventricle. Thoracotomy: Transposed aorta seen. Pulmonary stenosis.

be concave or convex, and the lungs may vary from a state of gross congestion to one of normal or deficient vascularity.

Yet there are three features that we consider important and if any one of these is found it strongly suggests the diagnosis of transposition.

(1) In 4 of the 14 cases the narrow vascular pedicle was seen.

(2) In 4 cases there was a long bulge of a special type in the left middle segment of the cardiac outline.

(3) In 4 patients a concave left middle segment was associated with pulmonary plethora.

A fourth feature may be mentioned. Pulmonary plethora occurring when there is neither a concave left middle segment, nor either of the first two signs, is suggestive of the diagnosis if the child is cyanosed. But it is not pathognomonic, for we have seen it in other conditions associated with cyanosis, e.g. persistent truncus arteriosus.

Table III analyses the cardiac silhouettes in terms of these four signs: 10 of the 14 children showed one or more of the three characteristic features and 2 of the 5 with pulmonary plethora without a pulmonary segment showed this without any of the other signs. In the remaining 2 , there was no direct X-ray evidence of the transposition. 
TABLE III

ANALYSIS OF THE X-RAY FINDINGS IN TERMS OF THE FOUR SIGNS DESCRIBED

\begin{tabular}{|c|c|c|c|c|c|c|c|c|c|c|c|c|c|c|}
\hline Name & M.S. & D.P. & M.C. & P.G. & G.G. & N.S. & P.L. & M.Sc. & L.T. & K.L. & R.W. & G.W. & L.M & M.F. \\
\hline $\begin{array}{l}\text { Narrow vascular pedicle .. } \\
\text { Long, prominent left mid seg- } \\
\text { ment . . } \\
\text { Pulmonary congestion plus } \\
\text { concave left mid segment } \\
\text { Pulmonary congestion with- } \\
\text { outconcaveleftmid segment }\end{array}$ & $x$ & $x$ & $x$ & $x$ & $x$ & $x$ & $x$ & $x$ & $x$ & $x$ & $x$ & $x$ & & \\
\hline
\end{tabular}

N.B. Normal or oligæmic lungs were shown by 5 children; only two of these (M.Sc. and L.M.) had pulmonary stenosis.

(1) The narrow vascular pedicle (Fig. 2A) can be a very striking feature although, like Eek (1949) we found it difficult to recognize a widening of the vascular shadow in the left anterior oblique position (Fig. 2B). The sign is not pathognomonic unless the narrow segment is quite definite and extends over a considerable length of the superior mediastinum: if it is short it is unwise to make a firm diagnosis for it can occur in other conditions and we have been deceived by its presence in a baby who had pure pulmonary stenosis and died in heart failure with cyanosis.

(2) The second characteristic sign occurs when the bulge of the transposed ascending aorta appears as the left middle segment (Fig. 3). To distinguish this from a prominent pulmonary artery, the length and shape of the segment is important rather than the degree of protrusion. The bulge extends from the left ventricle as an almost smooth upward continuation of its curve and may reach nearly as high as the sterno-clavicular joints. Consequently it often occupies the position of both the normal pulmonary and aortic segments. Under the fluoroscope, aortic pulsation can be seen all along the curve. It must be distinguished from the thymus and from segmental lesions of the left upper lobe.

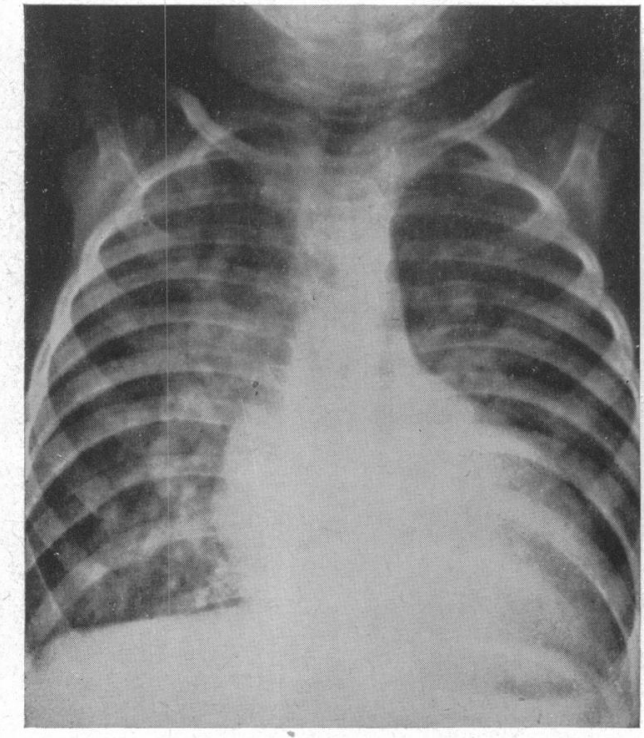

A

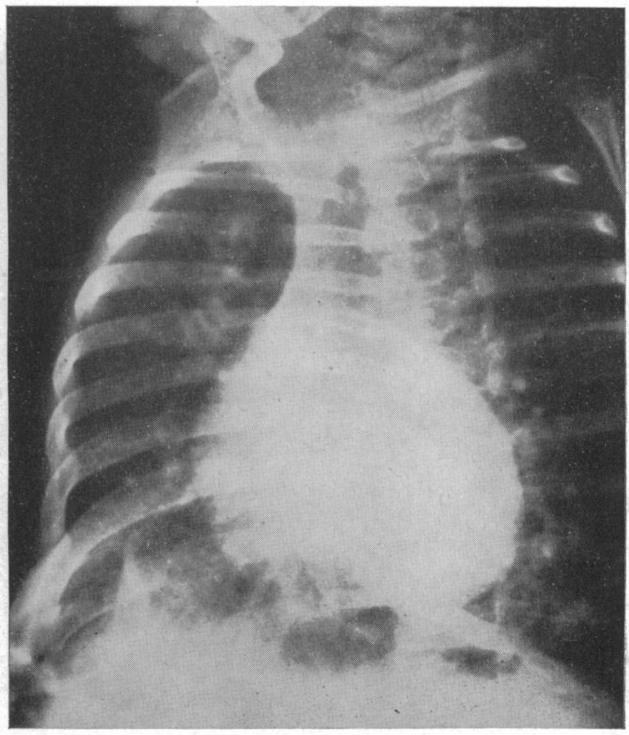

B

Fig. 2 (A).-The narrow vascular pedicle. Note the associated concave left middle segment and the pulmonary congestion. (B) The same child in the left anterior oblique position. There is no widening of the vascular pedicle. False impression of left ventricular enlargement. 
(3) The third characteristic sign, the association of pulmonary plethora with a concave left middle segment, is due to a misplaced pulmonary artery. The concavity cannot indicate a small pulmonary artery because the lungs are plethoric. The sign is often associated with a narrow vascular pedicle (Fig. 2A), but occurred twice as an isolated phenomenon. By itself (Fig. 4), it is not so reliable as either of the first two signs, for it may be found in such conditions as persistent truncus arteriosus.

With the above reservation, any one of the three signs strongly suggests the diagnosiswand, in practice, it is usual to find more than one sign. The absence of pulmonary plethora does not exclude the diagnosis of transposition. In 5 of the 14 children there was no congestion; in two this was due to a complicating pulmonary stenosis but there was no stenosis in two (or possibly three) others.

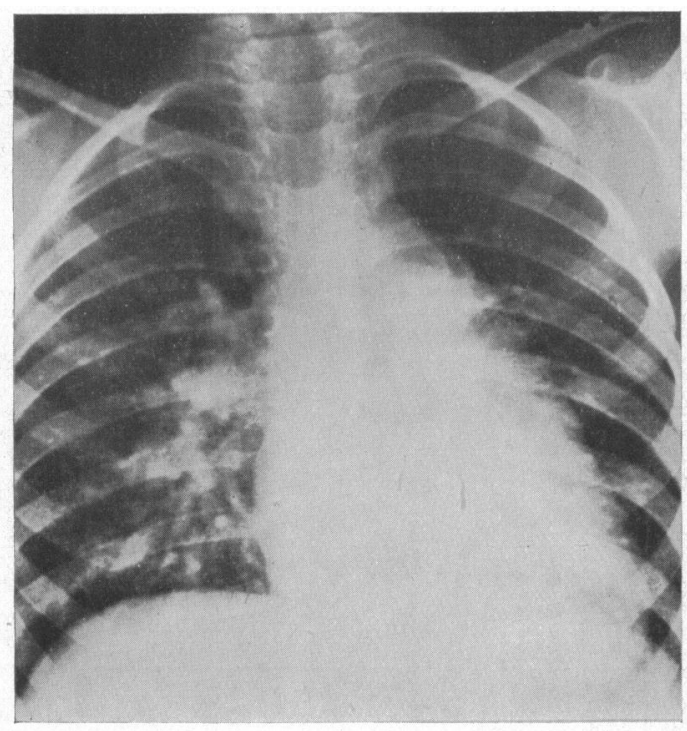

FiG. 3.- The transposed ascending aorta may produce a long bulge in the left middle segment.

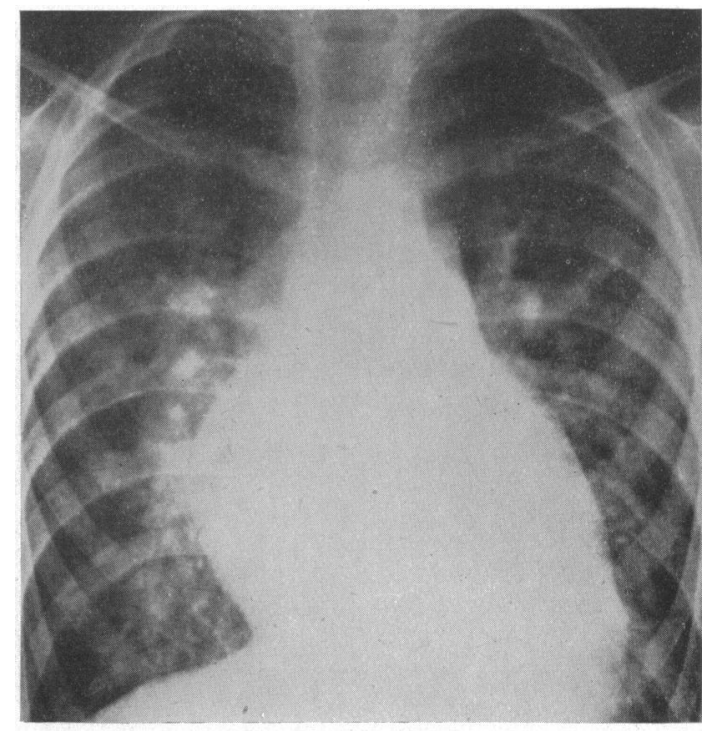

FIG. 4.-A concave left middle segment associated with pulmonary congestion may occur without the appearance of a narrow vascular pedicle.

In the left anterior oblique position, backward projection is commonly greater than forward projection of the heart (Fig. 2B). Ordinarily this would indicate that the left ventricle is larger than the right. On one occasion the discrepancy was so great that we thought the child had tricuspid atresia and a non-functioning right ventricle. But, as Taussig (1947) points out, in transposition the aorta is displaced anteriorly so that a false indication of relative ventricular sizes is obtained and necropsy shows that the right ventricle is in fact the larger. Although left atrial enlargement has been demonstrated twice, we have failed, as a general rule, to recognize the atrial dilation that is so prominent a feature at necropsy. On two occasions there was in the barium-filled œsophagus an extra impression of the type seen with a left-sided origin of the right subclavian artery.

Differential diagnosis from Fallot's tetralogy is of great practical importance. It is relatively easy if the lungs are congested, but may be very difficult when a child with transposition has normal or decreased pulmonary vascularity. It should be pointed out that it is practically impossible to assess by fluoroscopy whether a baby has pulmonary plethora or oligæmia, and that good films are essential. When the pulmonary vessels are oligæmic, unmistakable narrowing of the vascular pedicle or recognition of a long aortic bulge in the left middle segment strongly favours a diagnosis of transposition; we have seen neither of these features in Fallot's tetralogy. Some assessment of the defects associated with complete transposition may be possible. Normal or oligæmic lungs 
suggest either that the two circulations are mixing via the foramen ovale and a patent ductus or that there is a complicating pulmonary stenosis. In a child that has survived the first year of life the latter is more probable, while in such an older child congested lungs probably indicate a ventricular septal defect.

Angiocardiography has been used to confirm the diagnosis in 6 of the children. The main findings may be summarized as follows. From the right ventricle diodone passes immediately into the aorta, filling it and its branches in high concentration. The heart empties quickly (in two to five seconds), and little or no contrast medium can be identified in the left heart chambers. Despite pulmonary plethora little diodone reaches the lungs. Indeed, we have been unable to identify the pulmonary artery and its bifurcation in the frontal projection.

The origin and course of the aorta are variable. Castellanos et al. (1950) describe four different patterns, but we have divided our cases into two common varieties.

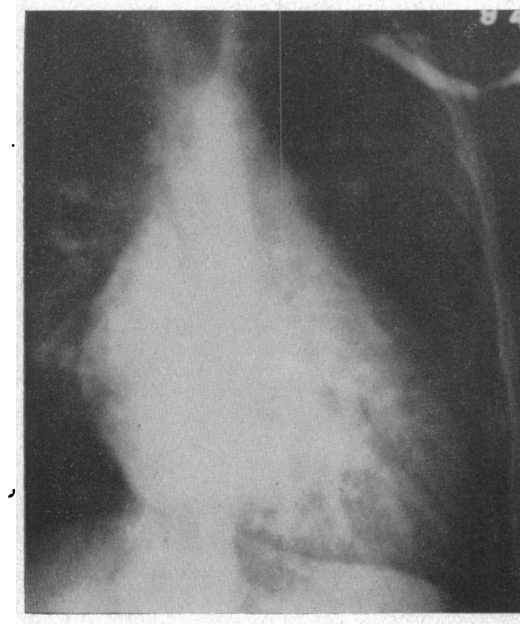

A

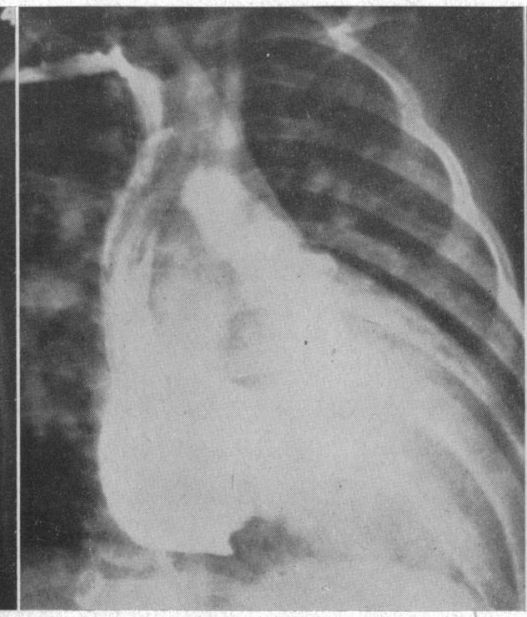

B

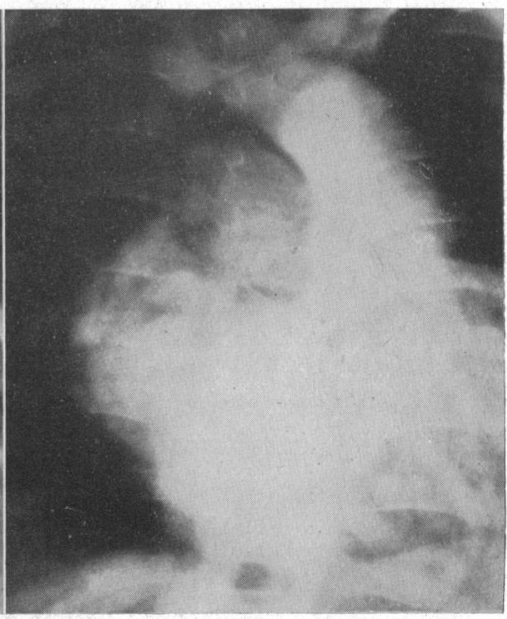

C

FIG. 5.-Angiocardiographic appearances in complete transposition. (A) Type 1. (The child shown in Fig. 4.) 2-second film. The aorta originates near the midline. (B) Type 2. (The child shown in Fig. 2A and B) $0 \cdot 5$-second film. The aorta originates to the left, from the outflow tract of the right ventricle. It ascends towards the right before arching over the left bronchus; hence it contributes little to the width of the superior mediastinum, which therefore appears narrow in Fig. 2A. (C) Type 2. Film at 1 second. The aorta ascends more vertically than in the previous example and produces a long bulge in the left middle segment, like that shown in Fig. 3.

Type 1. In 2 children the aorta arose near the midline and arched normally, as in Fallot's tetralogy (Fig. 5A). Campbell and Hills (1950) suggest that this indicates partial transposition, but in both of these children necropsy proved it to be complete.

Type 2. In 4 children the root of the aorta lay further to the left, in the position normally occupied by the main pulmonary artery (Fig. 5B and 5C). The aorta ran upwards and more or less obliquely to the right, and then arched over the left bronchus; occasionally it may cross the right bronchus (Castellanos et al., 1950). Because this pattern is quite distinctive we consider that the anterior-posterior projection is the position of choice for angiocardiography when transposition is suspected.

It appears likely that the main difficulty in angiocardiographic diagnosis would be to distinguish Type 1 transposition, with poorly vascular lungs, from Fallot's tetralogy with pulmonary atresia. This problem has not yet confronted us. The course of the aorta explains the direct X-ray signs. Where, in Type 2 transposition, the aorta ascends almost vertically and runs only slightly towards the right, it forms the characteristic bulge on the left heart border (Fig. 5C).

Taussig explains the narrow vascular pedicle on the ground that the pulmonary artery, displaced 
to the right, lies almost directly behind the aorta. This would account for Cases of Type 1 transposition with narrow great vessels but we have not seen this combination. We believe that the sign is seen in Type 2 when the ascending aorta takes a nearly horizontal course to the right and so contributes little to the width of the superior mediastinum (Fig. 2A and 5B).

Although we have observed no ill effects, angiocardiography in complete transposition is not without risk. Diodone enters the cerebral circulation in high concentration and Broman and Olsson (1949) have shown in the rabbit that this can upset cerebral vascular permeability. Apparently permanent disturbances of the electro-encephalogram have been observed and it is clearly important to establish a less hazardous method of diagnosis. Recognition of the direct radiographic appearances that we have described may reduce the need for angiocardiography, although we believe it justifiable when the diagnosis is in doubt.

\section{ELECTROCARDIOGRAPHY}

The electrocardiographic picture is not specific and may be indistinguishable from that found in Fallot's tetralogy. The electrical axis shows considerable variation but usually lies within the range of right ventricular preponderance. Chest leads show that there is often clockwise rotation of the heart so that leads V2-V6 may lie over the epicardial surface of the right ventricle. Incomplete right bundle branch block has been seen once, in a patient thought to have a ventricular septal defect. Characteristically the $\mathbf{P}$ waves are tall and peaked in the standard limb leads, especially in lead II. This presumably reflects the considerable atrial dilation that is a feature of the condition.

\section{Cardiac Catheterization}

We have examined only three cases of transposition by right heart catheterization as we have found angiocardiography a more valuable diagnostic procedure when dealing with small cyanotic children. But, as Bing et al. (1947) have also pointed out, catheterization may help to distinguish the nature of associated defects. Left-to-right shunts through septal defects will raise the oxygen saturation of blood in the right side of the heart and it may be possible to pass the tip of the catheter through the defect, although this is often difficult in infants with such small veins that the catheter has to be introduced at the groin. For this reason we failed on one occasion to identify a ventricular septal defect (V.S.D.) that was subsequently disclosed at necropsy. In another child, what we had identified as a V.S.D. turned out to be a sinus between right ventricle and left atrium. In older patients it is easier to pass the catheter through the defect and onward into the pulmonary artery so that pressures in the various cavities may be compared. Right ventricular pressure is alway high. If there is a V.S.D. the pressure in the right ventricle tends to exceed that in the left and in these circumstances aortic pressure is higher than that in pulmonary artery (Wood, 1950). However, if there is pulmonary stenosis as well as a V.S.D., or if the ventricular septum is intact and circulation depends on a valvular foramen ovale and patent ductus arteriosus, then pressure in the left ventricle and pulmonary artery is likely to be higher than that of the right ventricle and aorta. Campbell and Suzman (1951) report left-to-right shunts through defects of the ventricular septum in 6 of their series; these cases were apparently not complicated by pulmonary stenosis, but may have been examples of incomplete transposition of the great vessels.

Oxygen saturation of blood in the right side of the heart is very low but corresponds closely to that in the brachial artery. It is to be presumed that in a child with transposition and a patent ductus the oxygen content of blood in the femoral artery will exceed that in the right brachial artery.

\section{Prognosis}

In a series of 123 cases Blalock and Hanlon (1950) found that the average age at death was only 19 months. If the six oldest patients were omitted from this series the average survival period was reduced to $5 \frac{1}{2}$ months. Taussig (1947) states that most of these infants die in the first few weeks 
after birth and rarely live for more than 14 months. On the other hand, Campbell and Suzman (1950) believe that the outlook can be " ... very different from Taussig's picture ... with its gloomy prognosis," and consider that, if a septal defect allows sufficient mixing for an infant to survive a year, there is no reason why life should not continue for a considerable period. There are records of such patients attaining their twenties and one man lived until he was 56 years of age.

The fate of our patients is summarized in Fig. 6. Although the numbers are small, the diagram gives the impression that there are two groups of cases. There is one group with a high mortality in infancy, and another group of patients who, having survived this dangerous first year, continue a precarious and limited existence. Thus there is need for some means of deciding to which group an infant belongs. Further, if so many children escape early death and are condemned to be severely handicapped for months or years, some method of relieving their distress is urgently required.

Fig. 6 also summarizes the most important cardiac defect occurring in association with the transposition in each patient. It can be seen that the prognosis is poor when a patent ductus arteriosus (D) is the principal additional defect, for all these patients died shortly after birth. Children with an unspecified (S) or a proved atrial (A) or ventricular (V) septal defect usually have a better chance of survival, especially if the defect is associated with X-ray demonstration of plethoric lung vessels $(\mathrm{X})$. The prognosis is much less satisfactory if the lungs are radiologically oligæmic (O).

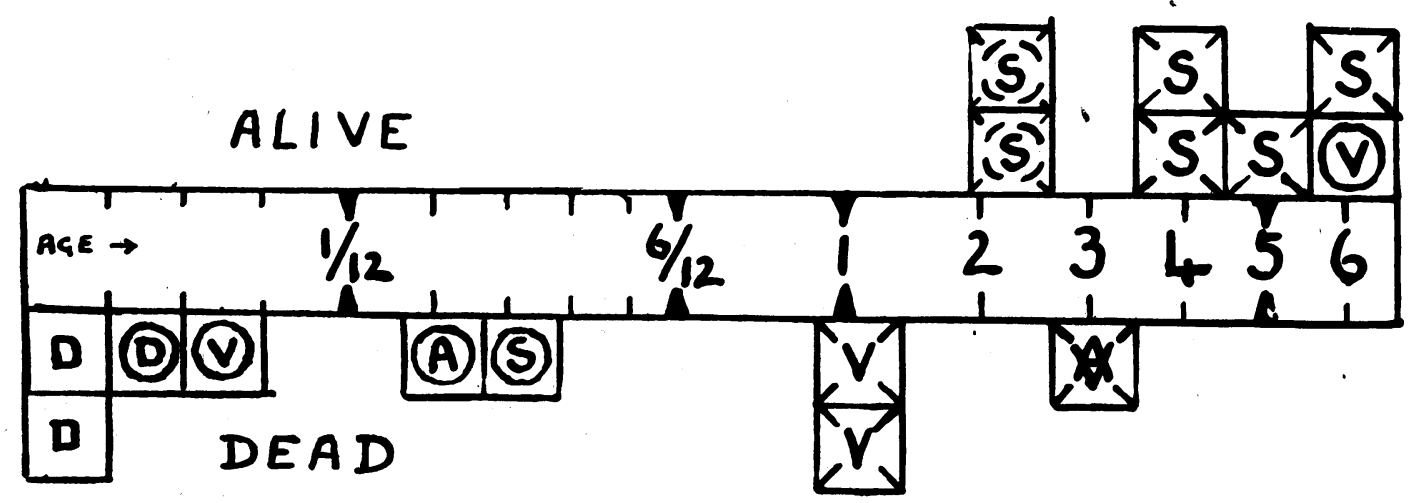

Fig. 6.-The ages and associated cardiac defects in our cases of transposition (See text).

Certain clinical and radiological features suggest that an infant has a patent ductus arteriosus and consequently indicate a poor prognosis. If the legs are consistently less cyanosed than the arms or torso, there can be no doubt about the diagnosis, but the sign is difficult to recognize. Marked venous engorgement in the neck and the development of generalized anasarca, together with radiologically clear lung fields, suggest a ductus rather than a septal defect. Rhythmic waxing and waning in the size of the right atrium is an X-ray sign described by Taussig that we have not yet seen.

We have failed to discover any clinical features that are certainly indicative of a septal defect and a relatively good prognosis. Children who had systolic murmurs also had septal defects but murmurs are notoriously misleading in this condition. We thought that a history of chronic cough or the finding of persistent rales might indicate pulmonary vascular congestion, but no such relationship could be established. X-ray evidence of pulmonary congestion is usual when there is a septal defect, but the combination is not invariable. Even cardiac catheterization sometimes fails to demonstrate a V.S.D. It seems to be easier to establish the case with the bad prognosis than to recognize the infant who will survive.

The frequency of venous congestion and the rarity of unconsciousness or fits suggest that death is more likely to result from myocardial failure than from cerebral anoxia. It is difficult to accept 
Brown's (1950) explanation that the cardiac enlargement is just " a result of shunts through persistent orifices," for rapid and progressive enlargement does not occur in such defects uncomplicated by transposition. It seems likely that myocardial ischæmia is the important factor responsible for enlargement, and it may be significant in this connection that at least one child had angina of effort, and that a two-day-old child had thrombosis of a coronary artery. Further, microscopic examination of the myocardium always shows necrobiotic changes in the heart muscle with loss of striation, nuclear degeneration, and hyaline changes; destruction of muscle structure is often severe.

When both coronary arteries arise from the pulmonary artery, life cannot be sustained for more than a few days. Similarly, in transposition, if the coronary arteries are irrigated with venous blood a short life is to be expected. This happens when transposition occurs with an intact ventricular septum and a patent ductus arteriosus, for oxygenated blood can pour freely into the descending aorta but it can never reach the ascending aorta and the coronary arteries. Patients with a septal defect have a better prognosis because oxygenated blood can enter the right ventricle and so reach the ascending aorta and coronary arteries. The way in which this happens demands more detailed consideration.

\section{Shunts in Transposition}

There has been wide acceptance of Taussig's (1947) suggestion that, when a V.S.D. is the chief associated abnormality, blood passes to and fro through the gap, accumulating on each side in turn until the rise in pressure reverses the shunt. We find it difficult to accept this conception. Such an unstable system should tend to reach equilibrium and if it did not, the patient should have periodic variation in degrees of cyanosis and phasic variation in the shape of the $T$ waves, neither of which we have observed. It is, however, a characteristic of these children that marked colour changes occur for no apparent reason even when the child is at rest. These changes were most marked in a child who had a large septal defect between the right ventricle and left atrium. In such a case, although there might be a flow from left to right in diastole or atrial systole, the maximal flow must have been constantly in the one direction, from right to left, during ventricular ejection. Taussig's contention that there is a "perpetual reversal in the direction of the shunt" is based on her observation of a periodic waxing and waning of the right atrium. But this is best seen when there is a valvular foramen ovale, an intact ventricular septum and a patent ductus arteriosus, circumstances in which, because of the valve, blood flow must be always from right to left atrium.

There are therefore grounds for believing that, in some cases at least, shunts in transposition are undirectional. We have investigated three varieties of shunt.

Type A Shunt. This is the shunt referred to above (a patent ductus arteriosus, an intact ventricular septum and a valvular foramen ovale). Pressure in the right atrium must exceed that in the left to ensure flow through the interatrial septum. On the other hand pressure in the pulmonary artery must be higher than that in the aorta so that blood can pass through the ductus into the descending aorta. This flow from the pulmonary artery into the aorta may account for the lack of pulmonary congestion that characterized our patients with this condition, while the high right atrial pressure may explain the systemic venous congestion and occasional œdema.

Type B Shunt. When transposition is combined with a V.S.D. we believe that the shunt is ordinarily from right to left ventricle. This suggestion is supported by some reports of pressure recordings (Wood, 1950a) but not by others (Campbell and Suzman, 1951). If the blood is being injected constantly into the pulmonary circulation as we believe, the smaller pulmonary branches will be congested, the pressure will rise and blood will be able to escape into the superior vena cava by way of the bronchial veins. That this happens is supported by the post-mortem finding of grossly congested lungs and Fig. 6 shows that, in all except three cases, children with septal defects had radiological evidence of vascular congestion in the lungs.

Type C Shunt. Three children with presumed ventricular septal defects had clear lung fields. At necropsy one was found to have a complicating pulmonary stenosis; in another no necropsy was allowed. The third child was shown by catheterization to have a shunt from left to right ventricle and at operation was seen to have pulmonary stenosis. In these cases oxygenated blood passes into the systemic circulation through the V.S.D. and back into the pulmonary circulation through the bronchial arteries or, if it is still open, the ductus arteriosus. Clinically, capillary congestion is systemic rather than pulmonary.

There are other varieties of shunt but we have had no opportunity to investigate them. Most important 
of these is the association of transposition with a widely patent atrial septum. According to Wood (1950b) the shunt in such cases is from left to right atrium and blood presumably returns to the left side of the heart either through a V.S.D. or through the bronchial arteries. We have seen only one case of this kind and at necropsy this child was found to have wide bronchial arteries.

We cannot accept the view that congestion of the lungs in transposition is due solely to there being no obstruction to the flow of blood to the lungs. Undoubtedly the congestion is often a result of heart failure, but sometimes it may be an indication that blood can flow more readily from the systemic to the pulmonary circulation than it can in the reverse direction. If this be true, it will have some bearing on the design of operations for the relief of symptoms in transposition.

\section{TREATMENT}

Blalock and Hanlon (1950) discussed the various measures they have taken to relieve the symptoms of transposition. They pointed out that no obstruction exists in either circulation and that the problem is to transfer blood from each circuit to the other. The most successful operation was one that opened the right superior pulmonary vein into the right atrium, created an atrial septal defect and anastomosed the proximal end of a subclavian artery to the distal end of a pulmonary artery. Two-thirds of the children so treated survived and improved.

If our reasoning is correct it should be the first objective of operative treatment to increase the oxygen supply to the coronary arteries; hence the different types of shunt will require different treatment.
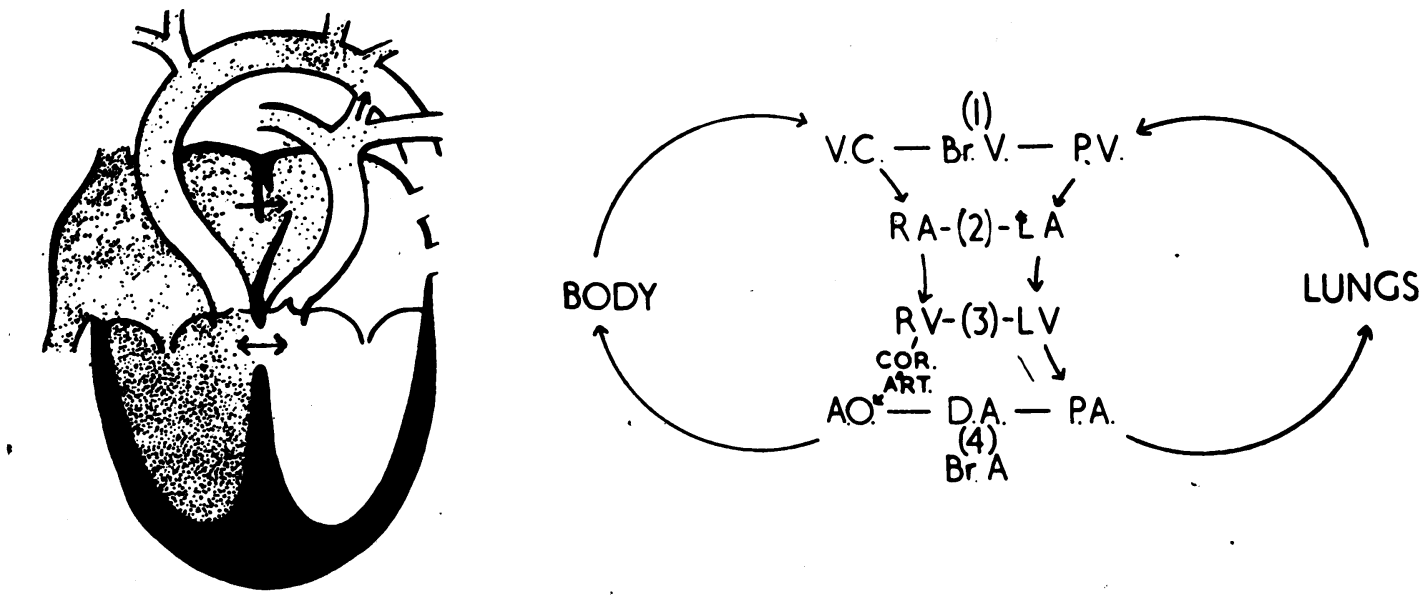

FIG. 7.-The circulatory route in complete transposition (See text).

Type A Shunt. Blood must necessarily pass from right to left through the valvular foramen ovale (No. 2 in Fig: 7). Oxygenated blood could best be diverted to the coronary arteries by creating a V.S.D. (3), if this operation were a less formidable undertaking. A less effective alternative would be to create a common arterial trunk by breaking down the aortic septum (4) as close to the coronary mouths as possible; the efficacy of the operation would be increased by closing the ductus arteriosus, providing of course that there were no break in the continuity of the aortic arch. Intervenous shunts (1) might be necessary as a final step to increase blood flow to the lungs; they could be produced between the right superior pulmonary vein and the superior vena cava, or by opening up the interatrial septum (Blalock and Hanlon, 1950). We have had no experience in the surgical treatment of this type.

Type B Shunt. Oxygenated blood reaches the right heart and the coronary arteries through the bronchial veins (1). This is a low pressure venous shunt, the efficiency of which could be improved by draining the right superior pulmonary vein into the right atrium (1) and by the creation of an atrial septal defect (2). Flow of blood from right to left could then be assured by joining the proximal end of a subclavian artery to the distal end of a pulmonary artery (Blalock and Hanlon, 1950). However, at the most oxygen would be obtained from only about a quarter of the available lung tissue. Despite this criticism, the operation has proved moderately successful in Blalock's hands and it is the best surgical procedure available for this form of shunt. Mr. A. L. d'Abreu has attempted the operation on two of our patients, both extremely ill. One 
child died on the operating table. The other stood the operation well and his colour was strikingly improved, but shortly after he had returned to the ward respiration suddenly stopped; necropsy failed to disclose any reason for this unexpected death.

Type C Shunt. Blood from the left side of the heart reaches the coronary arteries by the most direct and effective route (3) but pulmonary stenosis reduces the flow of blood through the lungs. The creation of an artificial ductus (4) by a straightforward Blalock subclavian-pulmonary artery anastomosis would greatly increase the pulmonary blood flow and consequently would improve oxygenation of blood in the coronary arteries. Mr. d'Abreu has carried out this operation in one of our patients with such success that we have wondered whether it might not be advantageous to create an artificial stenosis of the pulmonary artery in cases with a patent ventricular septum. Blalock and Hanlon (1950) have had the same experience and have considered the same possibility.

None of the operative procedures suggested is entirely satisfactory. Unfortunately it is at present impossible to transfer the great arterial trunks to their proper ventricles because of the position of the coronary arteries. An alternative operation would be to transpose the great veins, draining all the pulmonary veins into the right atrium and the two venæ cavæ into the left atrium. The technical difficulties would be tremendous, but herein lies a challenge to surgical skill that surely will be accepted.

\section{SUMMARY}

Transposition of the great vessels is second only to Fallot's tetralogy as a cause of cyanosis. The prognosis is poor, but a considerable number of children survive more than three years. Diagnostic features are reviewed in the light of 16 cases and new criteria are suggested for radiological diagnosis.

The importance of myocardial anoxæmia as a factor affecting prognosis is stressed and the theoretical aspects of operative treatment are considered.

\section{REFERENCES}

Bing, R. J., Vandam, L. D., and Gray, F. D., Jnr. (1947). Bull. Johns Hopkins Hosp., 80., 107, $121,323$.

Blalock, A., and Hanlon, C. R. (1950). Surg., Gynac. and Obst., 90, 1.

Broman, T., and Olsson, O. (1949). Acta Radiol., 21, 321.

Brown J. W. (1950). Congenital Heart Disease. Staples, London.

Campbell, M., and Hills, T. H. (1950). Brit. Heart J., 12, 65.

- and Suzman, S. (1950). Brit. Heart J., 12, 201.

- (1951). Circulation, 4, 329.

Castellanos, A., Pereiras, R., and Garcia, O. (1950). Amer. J. Roentgenol., 64, 255.

Eek, S. (1949). Morbus Caeruleus, edited by Mannheimer. E. Karger, Basle.

Emerson, P. W., and Green, H. (1942). J. Pediat., 21, 1.

Hanlon, C. R., and Blalock, A. (1948). Ann. Surg., 127, 385.

Keith, J. D. (1948). Canad. Med. Assoc. J., 58, 247.

Kerley, P., and Shanks, S. C. (1951). Text book of X-ray Diagnosis by British Authors. Lewis, London.

Mannheimer, E..(1949). Morbus Caeruleus. Karger, Basle.

Taussig, H. B. (1947). Congenital Malformations of the Heart. Commonwealth Fund, New York.

- (1949). Proc. Amer. Heart Assn., June.

Wood, P. (1950a). Brit. med. J., 2, 693.

- (1950b). Diseases of the Heart and Circulation. Eyre and Spottiswoode, London. 